\title{
자율이동로봇의 영상인식 미로탐색시스템 \\ Maze Navigation System Using Image Recognition for Autonomous Mobile Robot
}

\author{
엄 기 환, 이 정 훈, 강 성 호 \\ (Ki Hwan Eom, Jeong Hun Lee, and Seong-Ho Kang)
}

\begin{abstract}
In this paper, the maze navigation system using image recognition for autonomous mobile robot is proposed. The proposed maze navigation system searches the target by image recognition method based on ADALINE neural network. The infrared sensor system must travel all blocks to find target because it can recognize only one block information each time. But the proposed maze navigation system can reduce the number of traveling blocks because of the ability of sensing several blocks at once. Especially, due to the simplicity of the algorithm, the proposed method could be easily implemented to the system which has low capacity processor.
\end{abstract}

Keywords : ADALINE, image recognition, maze navigation system, autonomous mobile robot

\section{I. 서론}

최근 정부의 "차세대 성장 동력이 될 10 대 산업” 중 지능 형 로봇, 삼성전자 경제연구소의 "미래를 이끌어갈 10대 기 술" 중 서비스 로봇, 등의 잇단 발표로 차세대 고부가가치 산업으로 지능형 자율이동로봇의 인식과 투자 및 연구의 필 요성이 대두되고 있다.

자율이동로봇이란 자신의 위치, 거리 등의 주변상항을 스 스로 인식 및 판단하여 움직이는 지능형로봇이다. 자율이동 로봇의 종류에는 주어진 규격의 미로벽 정보를 인식하여 최 단거리를 판단하고 목표점에 이르는 마이크로 마우스, 카메 라를 이용하여 자신의 위치와 공의 위치 등을 판단하여 상 대의 골대에 골을 넣는 축구 로봇, 애완 로봇, 청소용 로봇, 구사용 로봇 등 다양한 형태의 로봇들이 있다[1-3].

자윯이동로봇에 필요한 기술에는 센서(sensor), 액추에이 터(actuator), 마이크로프로세서(microprocessor), 프로그래밍, 제어기설계, 구조설계 등 다방면에서 고난도의기술이 필요 하다[3].

자율이동로봇의 주변상황 인지를 담당하는 센서부는 적 외선센서, 초음파센서, 터치(touch)센서 등이 주로 사용되고 있다. 그러나 이러한 센서들은 감지 범위가 지협적이고 외 란에 약해 많은 정보롤 추출하기에는 미약한 면이 있다. 이 러한 이유로 한번에 넓은 범위를 정확하게 측정할 수 있는 비젼(vision)센서로서 카메라를 이용한 위치판단, 주변 상황 판단 등이 최근 연구의 대상이 되고 있다. 최근 컴퓨터가 보급됨에 따라 화상채팅용 CMOS방식 카메라의 기술이 소 형, 경량화 되어 있으며 가격 또한 저가이므로 기존의 센서 와 비교하여 많은 경쟁력을 가지고 있다. 이러한 비젼센서 를 이용한 기술은 앞으로 널리 보급될 모바일 로봇의 호율

\footnotetext{
* 책입저자(Corresponding Author)

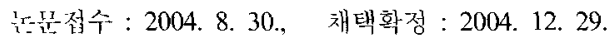

엄기환, 강성호 : 동국대학교 전자퐁학과

(kihwanum(@dgu.edu/ksh7209@dgu.edu)

이정훈 : 삳성전자(주)(ljhoon99@orgio.net)
}

적인 이용을 위한 필수적인 기반 기술이다. 최근에 이 기술 의 필요성을 인식하여 국내 - 외 여러 곳에서 연구가 시작되 고 있으나, 아직 뚜렷한 성과가 나타나 있지 않다. 또한 현 재 연구되고 있는 대부분의 영상 인식법은 고속, 고용량의 컴퓨터상에서 특징점 추출 등의 전처리기와 복잡한 인공지 능 등의 알고리즘을 적용시켜 인식률을 높이는 데에만 초점 을 맞추어 진행되고 있대[4-8].

그러나 자율이동로봇과 같이 독자적으로 움직이는 이동체 에는 상대적으로 속도와 용량이 작은 마이크로프로세서 레 벨에서 영상인식이 이루어져야 하므로 좀 더 단순하고, 계산 량이 적으면서 인식률을 개선시키는 방법을 취해야 한다.

본 논문에서는 이러한 자율이동로봇의 기존 센서 방식의 비효율성과 새로운 형태의 기술을 발전시기 위하여 미로 정 보 인식을 위한 센싱(sensing)방법으로, 화상카메라와 신경회 로망을 이용한 영상인식 시스템을 제안한다.

제안한 영상인식 미로탐색시스템은 미로의 벽정보 인식 을 위하여 카메라에서 받은 영상데이터를 신경회로망을 이 용한 영상인식방식으로 구현한다. 기존의 적외선센서 방식 은 정해진 미로의 목표점을 찾아가는 자율이동로봇인 마이 크로 마우스의 주행미로에서 한번에 현재 위치의 한 블럭 벽 정보만을 감지했기 때문에 가지 않아도 될 영역을 들어 가 탐지해야하는 불필요성을 가지고 있다. 그러나 제안한 영상인식 시스템은 한번에 여러 블럭을 감지할 수 있어 로 봇의 주행 블록수를 감소시킬 수 있다. 또한, 저용량의 마이 크로프로세서를 이용한 독립적인 임베디드 시스템(embedded system)에서 처리할 수 있도록 인공자능 알고리즘을 단순화 시켜 적용한다. 즉, 제안한 자율이동로봇의 기술은 PC 기반 처리가 아닌 상대적으로 저용량인 마이크로프로세서 레벨에 서도 그 기능을 충분히 활용할 수 있는 실용적인 기술이다.

제안한 영상인식 시스템의 유용성을 확인하기 위하여 미 로영상판별실험 및 자율이동로봇의 영상인식 미로주행실험 을 통하여 기존의 적외선센서 방식과 미로탐색시간에 대하 여 비교 검토한다. 


\section{II. 제안한 영상인식 미로탐색 시스템}

제안한 영상인식 미로탐색시스템은 카메라와 신경회로망 을 이용하여 미로의 벽 정보 주변상황을 인지하는 방법으 로, 한번에 넓은 범위의 영역을 비교적 외란에 영향을 받지 않고 처리할 수 있다. 카메라를 이용한 미로탐색시스템은 전방 수 블록의 앞벽과 옆벽을 인식할 수 있으므로 전방과 측방이 막힌 블록을 주행을 하지 않고도 미로를 탐색할 수 있어 효율적이다.

그러나 카메라를 이용한 시스템은 영상인식 알고리즘이 복잡하기 때문에 계산량이 커져서 상대적으로 적은 횽량의 마이크로프로세서를 사용하는 자율이동로봇에 구현하기가 쉽지 않다. 특히 영상인식에 많이 사용되는 신경회로망 알 고리즘은 뉴런수가 증가함에 따라 계산량이 지수적으로 증 가하므로 자율이동로봇에 사용하기위해서는 신경회로망이 갖는 장점을 살리고 그 구조가 최소화가 되도록 해야 한다. 제안한 영상인식 시스템의 영상인식부의 구성은 그림 1 과 같다. 제안한 시스템은 그림 1과 같이 카메라를 통해 얻 은 미로의 영상을 영상처리보드에서 캡쳐(capture)하고 이를 신경회로망 알고리즘이 장착된 마이크로프로세서에서 처리 및 인식하여 미로의 목적지까지 주행하는 영상인식 자율이 동로봇 시스템이다.

제안한 영상인식 방식은 화상카메라를 이용하여 영상이 미지를 $320 \times 240$ 의 해상도를 갖는 RAW파일로 받아 신경회 로망을 이용하여 벽의 유무를 판단한다. 제안한 자율이동로 봇에 적용되는 영상인식 시스템은 적은 용량의 마이크로프 로세서에서도 충분히 적용될 수 있도록 구조가 간단하고, 계산량이 작어서 액추에이터 구동, 센서감지, 판단 등의 처 리를 동시에 해야 하는 마이크로프로세서에 부담이 적게 설 계 되었다. 영상인식 시스템은 카메라, 영상처리보드, CPU 부, 구동부 등으로 이루어졌고, 영상인식은 원 영상을 분할, 2진화, 영상 크기(scale)축소 등의 전 처리(preprocessing)과정 을 거쳐 신경회로망을 이용하여 벽정보를 검출한다.

1. 전처리기

제안한 영상인식 시스템에 사용되는 전처리기는 $320 \times 240$ 의 영상 중에서 필요한 부분만 잘라내는 역할과 일정의 임 계값(threshold)를 주어 벽면과 바닥을 구분하는 역할 그리고 블록의 크기를 균일화하는 역할을 한다. 전처리기의 처리과 정은 그림 2 와 같다.

그림 2에서 제안한 영상인식 시스템의 전처리기의 과정 은 다음과 깉이 4 단계로 처리된다.

1) 원래의 영상에서 미리 정해진 비례 값으로 자율이동로 봇의 전방 3 개의 해당 블록을 앞, 좌, 우 블록의 픽셀로 분 할한다.

2) 원 영상 $(320 \times 240)$ 을 2 진 영상화 한다. 이때의 임계값을 기준으로 그 이상이면 흰색, 그 이하면 검은색으로 처리한 다.

3) 3 개의 각 블록은 원근감에 의해서 크기가 틀려지므로 신경회로망 처리를 단순화시키기 위하여 $80 \times 30$ 크기로 정 합을 시킨다.

4) $80 \times 30$ 영상을 왼쪽 벽, 앞 벽, 오른쪽 벽 각각 $20 \times 15$ 크기의 영상으로 분할한다.
최종적으로 전처리기에서 출력되는 영상은 한 블록당 $20 \times 15$ 크기의 세 개의 영상을 만들어낸다.

2. ADAL INE을 이용한 영상인식 알고리즘

전처리기에서 추출된 영상데이터에서 벽 정보를 인식하 기 위하여 최근 영상인식분야에서 많은 연구가 이루어지고 있는 신경회로망 알고리즘을 사용한다. 카메라를 이용한 미 로주행 자율이동로봇에 사용하는 신경회로망 알고리즘은 미 로의 인식률이 높고 계산량이 적을수록 좋기 때문에 ADALINE(ADAptive LInear NEuron) 신경회로망을 사용한다.

ADALINE은 은닉층이 없고 입력층과 출력층만으로 이루 어진 신경회로망으로 학습규칙은 LMS(Least Mean Square) 법을 사용한다. ADALINE 신경회로망의 출력은 벽의 유무 를 나타내는 하나의 뉴런이다. 미로의 벽을 인식하는 알고 리즘은 벽의 유무를 구분하기 때문에 선형분리가 가능하며 단층신경회로망인 ADALINE으로도 충분히 분리할 수 있다.

ADALINE 신경회로망의 구조는 그립 3과 같다.

제안한 영상인식 방식은 하나의 영상으로 최대 전방의 3 개 블록을 검출할 수 있고 각 블록 당 3 개(왼쪽, 전방, 오 른쪽)의 벽을 인식한다. 만일 로봇의 앞에서부터 첫 블록의 전 방벽이 막혀있다면 그 뒤의 벽은 인식하지 않는다.

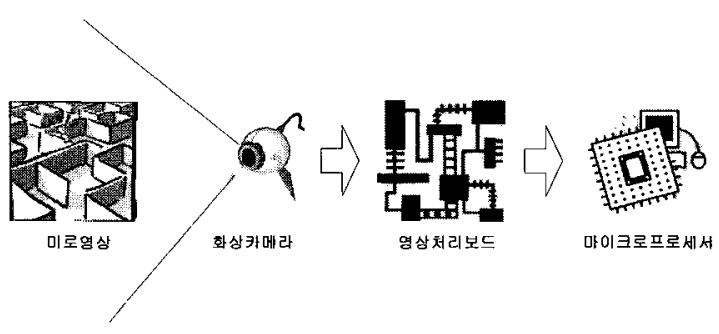

그림 1. 제안한 영상인식 시스템의 영상인식부.

Fig. 1. Proposed image recognition system.

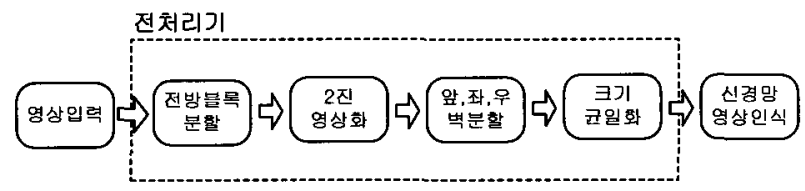

그림 2. 원 영상의 전처리과정.

Fig. 2. Preprocessing of original image.

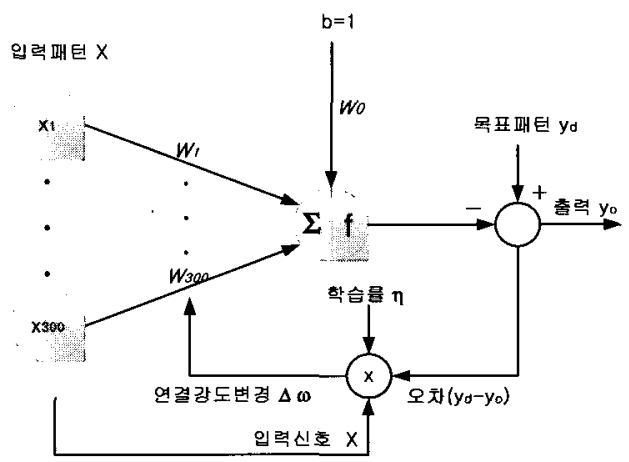

그림 3. ADALINE 신경회로망의 구조.

Fig. 3. Structure of ADALINE neural network. 
$\mathrm{ADALINE}$ 신경회로망의 입력충은 영상의 픽셀수인 300 개 $(20 \times 15)$ 의 입력뉴런을 가지며 이 입력뉴런을 $x_{1}, x_{2}, \ldots$, $x_{300}$ 이라 정의한다. 입력은 각 입력에 대한 가중치 $w_{1}$ $w_{2}, \ldots, w_{300}$ 이 곱해저 출력뉴런에 가해진다.

출력뉴런의 입력으로 가해지는 가중 합을 net라 정의하 면, 출력층 뉴런의 출력 $y_{0}$ 는

$$
y_{0}=f_{(n e t)}
$$

로 되고, 이것이 바로 ADALINE 신경 회로망의 출력이 된 다. ADALINE 신경회로망은 활성함수로 (2)와 같은 선형함 수(linear function)를 사용하기 때문에 계산량을 더욱 줄일 수 있다.

$$
f(\text { net })=\text { purelin }(\text { net })
$$

purelin()는 선형함수를 나타낸다. ADLAINE 신경회로망 의 목적함수인 오차신호는 (3)과 같다.

$$
e=\frac{1}{2}\left(y_{d}-y_{o}\right)^{2}
$$

여기서 $y_{d}$ 는 목표 패턴으로 벽의 유무를 나타낸다. 오차를 줄이기 위한 연결 강도 조정식은 $\mathrm{LMS(least} \mathrm{mean}$ square)학습규칙을 이용하여 다음과 같이 쓸 수 있다.

$$
w_{n+1}=w_{n}+\eta\left(y_{d}-y_{0}\right) x
$$

이 연결강도 조정식을 이용하여 ADALINE 신경회로망은 학습을 하게 된다.

ADALINE 신경회로망을 이용한 영상인식부는 전처리기 에서 처리한 $20 \times 15$ 크기의 좌, 우, 앞 영상을 판독해야하므 로 세 개의 ADALINE 신경회로망으로 구성된다. 각각의 ADALINE 신경회로망의 학습은 카메라를 장착한 자율이동로 봇이 미로위에서 찍은 영상들을 목표패턴으로 하여 $\mathrm{PC}$ 상에 서 수행되고 좌, 우, 옆벽에 대한 각각 300 개의 연결강도가 조정된다. 이렇게 학습된 연결강도를 자율이동로봇에 이식하 고 이식한 후 자율이동로봇의 미로탐색 시 ADALINE 신경 회로망은 학습을 하지 않고 전방향 처리기로서 작동함으로 써 상대적으로 용량이 적은 마이크로프로세서에서의 영상 처리를 빠르게 하도록 설계한다

\section{III. 실험 및 결과}

1. 미로 영상 인식 실험

미로 영상인식 실험은 자율이동로봇이 미로주행을 하기 전에 여러 형태의 미로영상을 제안한 인식 신경회로망 시스 템으로 학습하여 벽의 정보 패턴을 인식하는 실험이다.

실험에 사용된 미로는 국제 마이크로 마우스 대회의 규격 에 맞는 미로로 폴대(pole)와 벽은 조립식으로 이루어져 있 다. 마이크로 마우스대회의 실전 미로는 $16 \times 16$ 블록이나 본 실험에서는 그림 3 과 같은 $4 \times 4$ 봃록의 미로를 사용하였다.

미로 영상인식 실험에 사용된 영상은 CMOS 방식의 카메 라를 장착한 자율이동로봇을 $4 \times 4$ 블록의 미로위에 놓고 찍 은 $320 \times 240$ 크기의 혹백 RAW 파일 형태이다. 미로 영상의

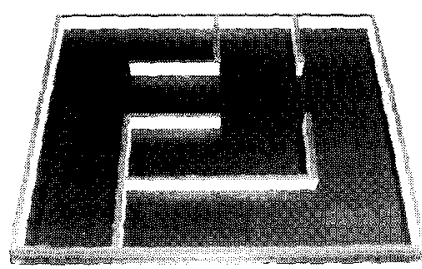

그림 3. 실험에 사용된 $4 \times 4$ 미로.

Fig. 3. $4 \times 4$ maze for experiment.

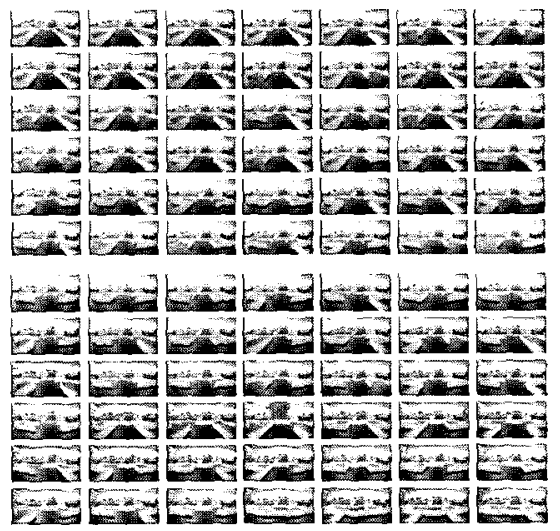

그림 4. 자율이동로봇에서 캡쳐된 미로영상.

Fig. 4. Maze images captured by autonomous mobile robot

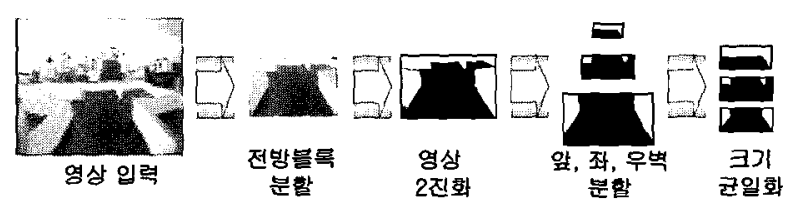

그림 5. 전처리과정.

Fig. 5. Preprocessing procedure.

인식은 PC 상에서 이루어지며 미로영상은 카메라를 장착한 로봇에서 캡쳐하여 하나씩 PC로 다운로드 하였다.

제안한 영상인식 시스템의 목표는 로봇 전방 세 블록의 벽 정보를 정확히 인식하는데 있다. 각 블록은 동, 서, 남, 북 네 방향의 정보가 있어야 한다. 따라서 세 블록인식, 두 블록인식, 한 블록인식이 있으며, 각 인식마다 전 벽 막힙, 한 벽 개방, 두 벽 개방 등으로 조합을 이루어 보면 가능한 조합 수는 84 개이다.

그림 4에 자율이동로봇에서 캡쳐한 미로영상들이 나타나 있다. 캡쳐한 영상은 전처리기에 의해 영상분할, 2 진영상화, 크기 균일화 등의 과정을 거친다. 전처리기에서 영상을 처 리하는 과정은 그림 5 와 같다. 이렇게 전처리기를 통과한 영상들은 그림 6 과 같이 $20 \times 15$ 크기의 영상이 된다.

그림 5 와 같이 미로의 원 영상을 전처리한 후 ADALINE 신경회로망의 영상인식방법으로 학습한다. 구성한 ADALINE 신겅회로망은 입력 뉴런 300 개 출력뉴런 1개의 단층 신경 회로망으로 이루어진다. 한 블록 당 왼쪽 벽, 앞 벽, 오른쪽 벽에 대한 세 개의 ADALINE 신경회로망이 각 벽의 유무를 
학습한다. 연결강도의 초기값은 모두 0 에서 1 사이의 랜덤 (random)값으로 하고 학습률은 0.01 로 고정하여 사용하였다.

활성함수는 선형함수를 사용하고 학습은 LMS(Least Mean Square) 학습규칙을 이용하였다. 학습조건은 목표함수 MSE (Mean Square Error)가 $1 \times 10^{-2}$ 이 될 때 까지 학습시켰다. 학습 후 각 $\mathrm{ADALINE}$ 신경회로망의 학습회수는 표 1과 같다.

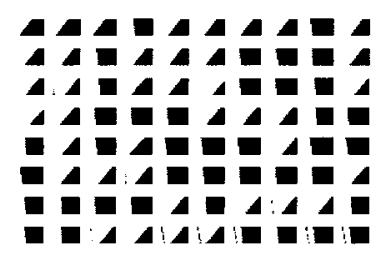

(a) The left wall

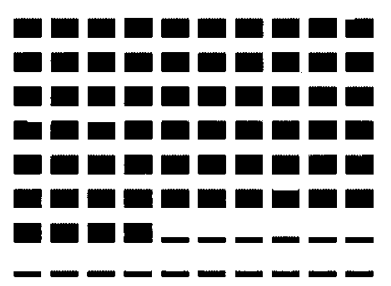

(b) The front wall

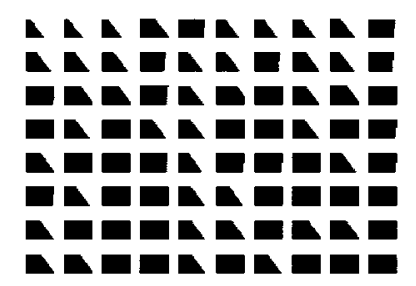

(c) The right wall

그림 6. 전처리기를 통과한 영상.

Fig. 6. Preprocessed images.

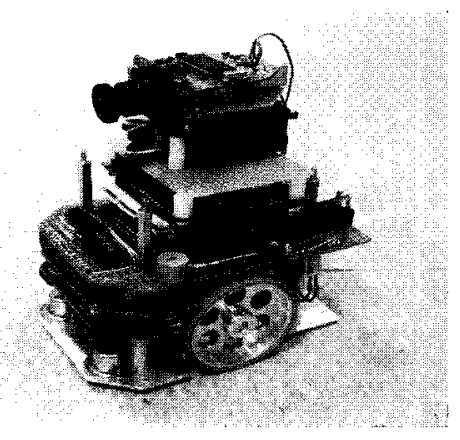

그림 7. 카메라를 이용한 자율이동로봇 사진.

Fig. 7. Picture of autonomous mobile robot with camera.

표 1. ADALINE 신경회로망의 학습회수.

Table 1. Number of learning iterations for ADALINE neural network.

\begin{tabular}{|c|c|c|}
\hline ADALINE 1(왼쪽) & ADALINE 2(앞) & ADALINE 3(오른쪽) \\
\hline 7470 & 1230 & 4524 \\
\hline
\end{tabular}

표 2. 카메라를 이용한 자율이동로봇의 시스템 사양.

Table2. Specification of autonomous mobile robot with camera.

\begin{tabular}{|c|c|}
\hline \multicolumn{2}{|c|}{ 카메라를 이용한 자율이동로봇의 시스템사양 } \\
\hline - Microprocessor & Intel $386 \mathrm{EX}, 32 \mathrm{MHz}$ \\
\hline - Memory & 2MB ROM, 512kB SRAM \\
\hline \multirow{2}{*}{ - Motor } & 일본 Oriental사의 \\
\hline & PK243(stepping motor)2개 \\
\hline - Total weight & $980 \mathrm{~g}$ \\
\hline - Battery & $9.6 \mathrm{~V}, 800 \mathrm{~mA}(1.2 \mathrm{~V} 8$ 개 $)$ \\
\hline - Motor 구동방식 & Pulse 구동 \\
\hline - frame & 자체제작 \\
\hline - Motor Driver & L298, SLA7024 \\
\hline \multirow{5}{*}{ - Camera \& 영상보드 } & Prochips 사의 PCA-3202 \\
\hline & CMOS with $300 \mathrm{~K}$ Pixel \\
\hline & $320 \times 240,160 \times 120,80 \times 60$ \\
\hline & Diagonal Filed of \\
\hline & View- $60^{\circ}\left(90^{\circ}\right.$ 렌즈로 교체 $)$ \\
\hline \multirow{2}{*}{ - 센서 } & 적외선센서 \\
\hline & (수광: ST1KL2, 발광: CL1L) 7조 \\
\hline - AD Converter & AD7828 \\
\hline - S/W Tool & Borland C 3.1 \\
\hline
\end{tabular}
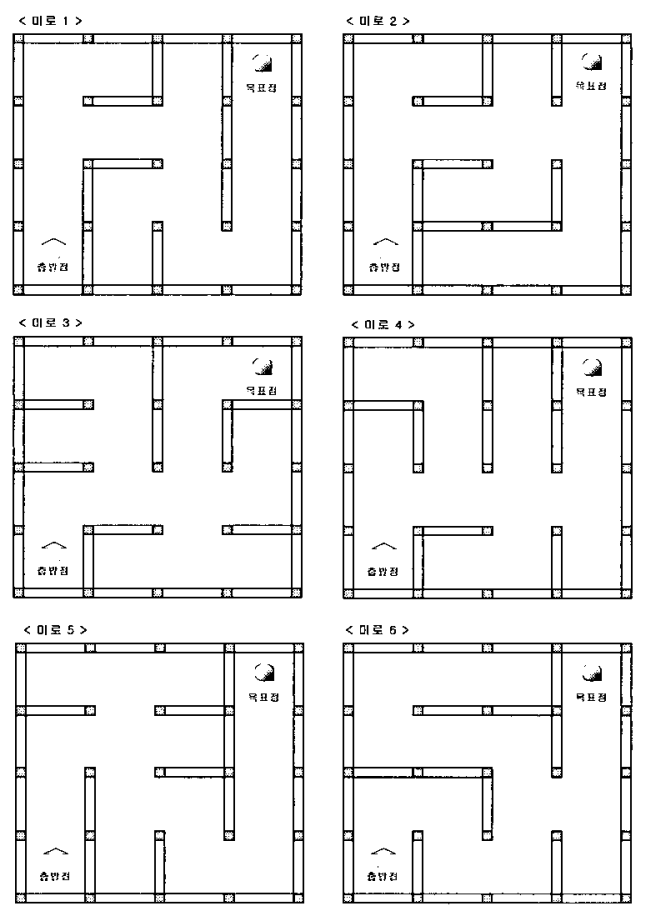

그림 8. 미로주행실험에 사용된 미로.

Fig. 8. Mazes used for navigation experiment.

표 3. 미로주행 결과.

Table 3. Experimental result of navigation.

\begin{tabular}{|c|c|c|c|c|c|c|}
\hline & 미로 1 & 미로 2 & 미로 3 & 미로 4 & 미로 5 & 미로 6 \\
\hline $\begin{array}{c}\text { 적외선 방식의 } \\
\text { 로봇 }\end{array}$ & 16 블록 & 12 블록 & 14 블록 & 18 블록 & 18 블록 & 20 블록 \\
\hline $\begin{array}{c}\text { 제안한 영상 } \\
\text { 인식 로봇 }\end{array}$ & 12 블록 & 8 블록 & 10 블록 & 10 블록 & 12 블록 & 16 블록 \\
\hline
\end{tabular}


표 1에서 ADALINE 1은 왼쪽 벽 식별을 위한 $\mathrm{ADAINE}$ 신경회로망, ADALINE 2는 앞 벽 식별을 위한 ADLAINE 신 경회로망, ADALINE 3는 왼쪽 벽 식별을 위한 ADLAINE 신 경회로망이다. 학습결과 앞 벽에 대해서 가장 빠른 학습 회 수로 식별함을 알 수 있다.

학습이 끝난 후 얻은 연결강도를 가지고 84 개의 미로영 상에 대하여 인식실험을 하였으며, 그 결과 $100 \%$ 인식함을 확인하였다.

\section{2. 자율이동로봇의 영상인식 미로주행실험}

미로주행 실험은 $4 \times 4$ 볼록 미로의 한쪽 끝에서 출발하여 대각선 끝 블록을 목표지점으로 주행하는 실험이다.

미로주행실험에서는 제안한 영상인식 시스템을 적용하여 6 가지의 서로 다른 $4 \times 4$ 미로를 주행하였다.

영상인식에 사용된 ADALINE 신경회로망의 초기값과 학 습롤은 미로영상인식실험에서 학습된 값을 사용하였고 하습 된 연결강도로 전방향 $\mathrm{ADALINE}$ 신경회로망을 구성하였다.

제작한 자율이동로봇은 다소 높게 설계되었는데 이는 향 후 주행 중에 좌·우의 옆 블록 등 카메라가 캡쳐하는 영상 내의 모든 블록을 인식할 수 있게 하기 위해서이다.

영상처리보드는 카메라에서 받은 영상을 RAW 파일 포맷 으로 변환해주는 기능을 한다.

카메라는 Prochips 사의 CMOS 방식의 웹카메라를 사용 하였다. 그러나 최근 상용화된 윕카메라는 화상채팅용이어 서 화각이 $45^{\circ}-60^{\circ}$ 이다. 화각이 좁으면 촬영 각이 좁아져 로 봇의 전방 첫 번째 블록을 캡쳐할 수 없기 때문에 화각이 $90^{\circ}$ 인 렌즈로 교체하여 사용하였다. 카메라와 영상보드를 이용하여 제작한 자율이동로봇의 사진은 그림 7과 같으며, 표2는 제작한 자율 이동 로봇의 시스템 사양이다.

위와 같이 제작한 자율이동로봇으로 그림 8과 같은 6가 지 형태의 미로에서 주행실험을 하여 기존의 적외선센서만 으로 주행한 결과와 제안한 영상인식 자윯이동로봇 시스템 으로 주행한 결과의 주행블록수를 비교 검토하였다. 미로주 행실험 시 사용한 미로탐색 알고리즘은 적외선 방식과 제안 한 방식 모두 일반 좌수법을 사용하였다.

표 3은 기존의 적외선센서로 미로주행을 한 것과 제안한 영상인식 방식으로 주행한 결과이다. 표 3 의 주행결과에서 처럼 제안한 영상인식 미로탐색시스템은 기존의 적외선센서 를 이용한 자욿이동로봇과 비교하여 평균 5 블록의 주행거리 를 단축하여 평균 주행 볼록수의 $30.6 \%$ 를 단축하였다.

이러한 결과는 적외선 센싱방식은 이동을 하면서 한번에 한 블록씩 근접한 벽을 센싱하여 전체 미로지도의 벽의 유 무를 기록하면서 목표점을 찾는다. 따라서 사방이 막혀 길 이 없는 구간조차 끝 블록까지 주행하여 정보를 판단한다. 반면 제안한 방식은 한번에 최대 세 블록까지 센싱하여 전 체 미로 지도의 벽 유무를 판단 및 기록하므로 막혀있는 구 간의 끝까지 주행하지 않고도 센싱 할 수 있다. 결국 주행 벌록 수를 감소 시켰다.

\section{V. 결론}

본 논문에서는 자율이동로봇의 기존센서 방식의 비호율 성과 새로운 형태의 기술을 발전시키기 위하여, 보다 효율
적인 미로탐색 시스템인 화상카메라와 신경회로망 영상인식 을 이용한 미로탐색시스템을 제안하였다.

제안한 영상인식 미로탐색시스템은 카메라에서 받은 영상 을 신경회로망 영상인식 방법을 이용하여 벼정보를 인식해 서 미로의 목표점에 칮아 가는 시스템이다. 제안한 방식은 기존 자율이동로봇에 사용된 적외선센서의 검출범위가 지협 적이고, 물체의 유무만 구분할 뿐 사물의 모양이나 구조 등 은 식별할 수 없는 단점을 보완하여, 상대적으로 감지범위가 넓은 카메라를 이용한 시스템으로 미로탐색 시 가지 않아도 되는 영역을 인지하여 미로 탐색시간을 줄이는 방법이다.

제안한 방식들의 유용성을 확인하기 위하여 미로영상 인 식실험 그리고 미로주행실험을 통하여 기존의 적외선 센서 방식과 그 성능을 비교 검토하였다.

미로 영상판별실험에서 $\mathrm{CMOS}$ 방식의 카메라로 찍은 84 개의 미로영상들을 $\mathrm{PC}$ 상에서 ADALINE 신경회로망을 이 용한 영상인식방법에 적용시켜 $100 \%$ 미로를 인식하였다.

미로주행실험에서는 $\mathrm{PC}$ 상에서 학습한 파라미터들을 제작 한 자율이동로봇에 인식시켜 여섯 개의 실제 미로 상에서의 주행실험을 한 결과 기존 적외선센서방식과 비교하여 $30.6 \%$ 의 블록수를 단축하여 목표점까지 정확히 찾아 이동 하는 것을 확인할 수 있었다.

이와 같이 실험결과 제안한 방식들이 기존의 방식보다 개선된 성능을 갖는 것을 확인하였다. 제안한 영상인식을 이용한 자율이동로봇은 기존의 센서방식보다 더 넓은 범위 를 검지하여 원거리에서의 미로 벽의 유무를 정확히 판단하 여 최단거리로 목적지를 찾아가는 우수성을 보여주었다.

또한, 본 논문에서 제안한 영상인식을 이용한 미로탐색시 스템은 지금까지 구현하기 어려웠던 인공지능 영상인식을 이웅한 자율이동로봇에 대해 적용함으로써 그 가능성과 대 안을 제시하였다. 특히, 기존의 여러 영상인식시스템들은 고 속, 고용량의 컴퓨터 기반 하에 개발되어 실제 산업현장이 나 상대적으로 저용량의 임베디드시스템에 적용하기가 사실 상 어려운 점이 많았다. 반면에 제안한 자율이동로봇의 기 술들은 마이크로프로세서 레벨에서도 적용될 수 있어 매우 실용적이라 할 수 있다.

\section{참고문헌}

[1] A. C. Schultz, "Using a genetic algorithm to learn strategies for collision avodiance an d local navigation," 7th Int, Symp on Unmanned, Untethered, Submersible Technology, Durham, NH, pp. 213-225, 1991.

[2] M. Drigo and U. Schnepf, "Genetics-based machine learning and behavior-based robotics: a new synthesis," IEEE Trans. on Systems, Man and Cybernetics, vol. SMC-23, no. 1, 1993.

[3] G. Li and S. J. Louis, "Designing control strategies for a simulated robot using non-randomly initialized genetic algorithms," Proc. ISCA 5th Int. Conf. on Intelligent Systems, pp. 145-149, ISCA Press, 1996.

[4] 이동욱, 심귀보, "분산유전알고리즘을 이용한 자율이동 로봇군의 행동진화," 제 5회 인공지능, 신경망 및 퍼지 
시스템 종합학술대회 발표논문집, pp. 127-130. 1996.

[5] K. S. Narendra, "Adaptive control of dynamical using neural networks in handbook of intelligent control," van Nostrand, 1994.

[6] L. Fausett, Fundamentals of neural networks, Prentice Hall, 1994.
[7] C. G. Looney, Pattern recognition using neural network, Oxford Univ. Press, 1997.

[8] S. S. Soliman, and S. Z. Hsue, "Signal classfication using statistical monents," IEEE Transactions on communications, vol. 40, no. 5, pp. 908-916, 1992.

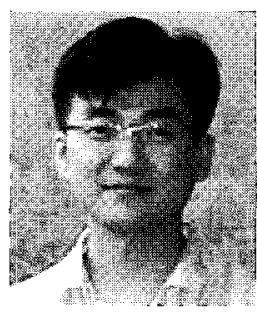

\section{이 정 훈}

1997년 동국대학교 전자공학과 공학사. 1999년 동국대학교 전자공학과 공학석 사. 2004년 동국대학교 전자공하과 공 학박사. 2004년 현재 삼성전자 DM사 업부 연구원. 관심분야는 자동제어, 퍼 지 이론, 신경회로망.

수. 관심분야는 시스템 응용, 의용전자, 인공지능 알고리즘.

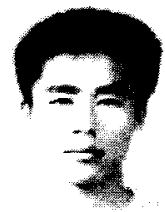

자율이동 로봇.

\section{강 성 호}

2000년 진주산업대학교 전자공학과 공 학사. 2002년 동국대학교 전자공학과 공학석사. 2002년 현재 동국대학교 전 자공학과 박사과정. 2003년 현재 밀리 미터파신기술연구센터 연구원. 관심분 야는 시스템 응용, 인공지능 알고리즘, 